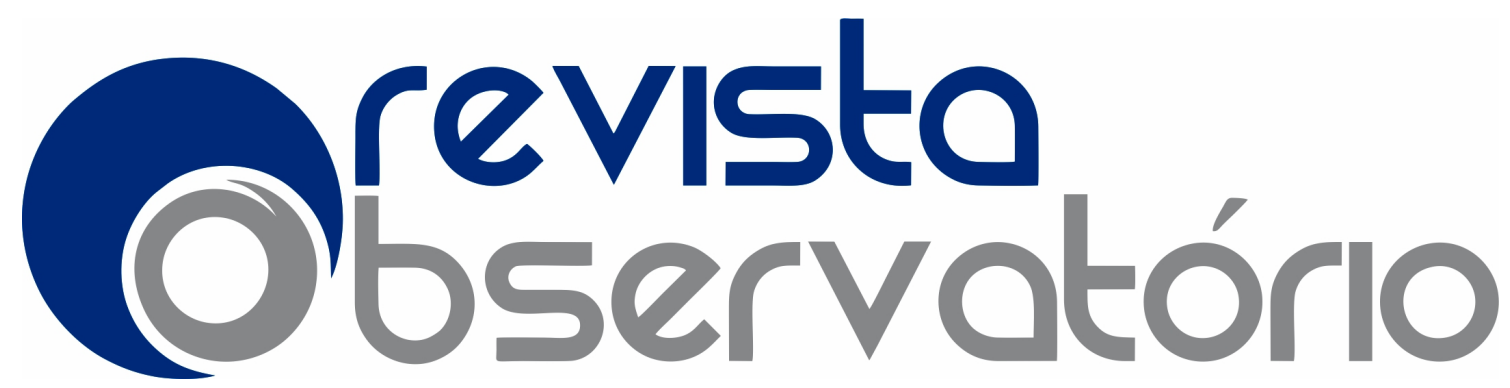

ISSN n² 2447-4266

Vol. 5, n. 6, Outubro-Dezembro. 2019

DOI: http://dx.doi.org/10.20873/uft.2447-4266.2019v5n6p26

\title{
NETNOGRAFIA E HUMANIDADES DIGITAIS: perspectivas e desafios
}

A Revista Observatório apresenta seu sexto número de 2019, com capa produzida pelo colega e artista Adriano Alves. Como parte do planejamento de 2019, a intensificação dos ajustes segue, o que tem resultado em uma maior visibilidade e citação da revista por parte dos leitores. Fechamos o ano de 2019 com os 10 artigos mais citados em destaque, o que gerou uma visibilidade grande, permitindo que a revista se destaque no meio acadêmico. (SPINELLI; SANTOS, 2018; BUENO; REINO, 2018; ELHAJJ; ESCUDERO, 2016; BERNARDO et al., 2015; CHIECHER et al., 2016; MOURA, 2017; VIANA; COSTA, 2017; MACHADO; COSTA; MORAES, 2018; NUNES; PORTO JUNIOR; MORAES, 2017; MELO, 2017; MIRANDA-PINTO; MONTEIRO; OSÓRIO, 2017). Esperamos que em 2020 tenhamos esse número ampliado!

O novo dossiê, intitulado NETNOGRAFIA E HUMANIDADES DIGITAIS: perspectivas e desafios, foi organizado pelos colegas Dr. Fagno da Silva Soares do CLIO \& MNEMÓSINE/IFMA e Núcleo de Estudos em História Oral - NEHO/USP e, do Dr. Jesus Marmanillo Pereira do Laboratório de Estudos e Pesquisa sobre Cidades e Imagens - LAEPCI/UFMA). O dossiê reuniu um coletivo de pesquisas e reflexões cujos objetos e perspectivas investigativas inscrevem-se sob a rubrica da etnografia ou Virtual Ethnography como sugere Christine Hine (2000) e suas 


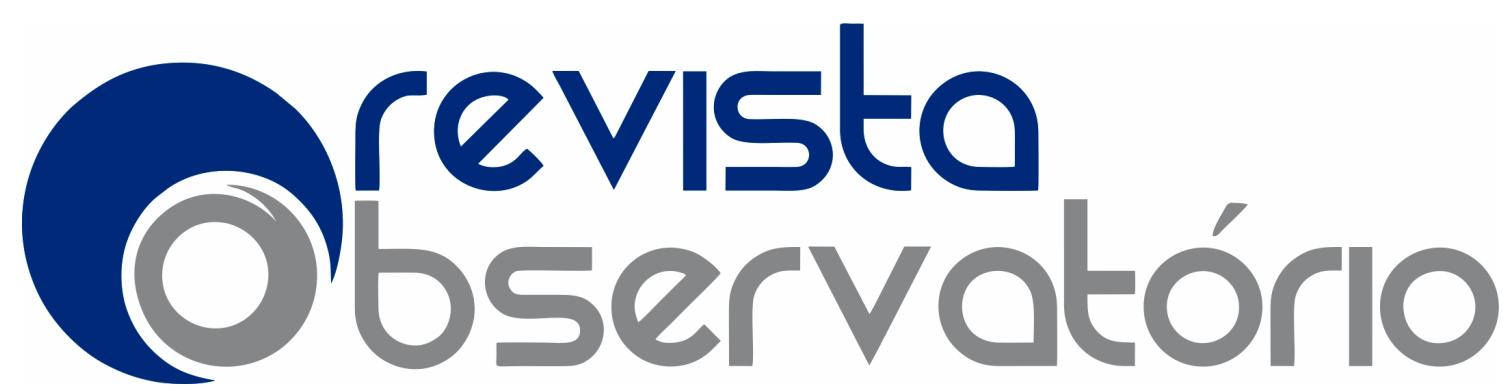

relações com o que temos chamado de Humanidades Digitais, enquanto ferramenta metodológica, técnica interpretativa ou prática investigativa acerca das comunidades digitais offline ou online apropriadas por uma análise investigativa no/do ciberespaço. Nesse sentido buscou-se criar um espaço de diálogo transdisciplinar na qual os usos na/da internet e seus impactos sóciodigitais possibilitam reflexões e narrativas no âmbito das percepções e das sociabilidades digitais, constituindo um campo no qual se aproximam a comunicação das humanidades.

Assim, as Humanidades Digitais aqui são compreendidas como zona interdisciplinar de interseção entre as tecnologias digitais e as ciências humanas em profusa transformação. Destarte, a prática netnográfica e mesmo autonetnográfica e as Humanidades Digitais, são entendidas aqui como meio, e como fonte nas quais se expressam representações da própria da sociedade imagética do primeiro quartel do século XXI, essencialmente informacional, sob esta esteira deste dossiê objetiva-se constituir um espaço orientado por um eixo verticial Netnografia e Humanidades Digitais em seus candentes e pueris embates conceituais e teórico-metodológico, bem como, em suas reverberações junto a repositórios digitais, curadorias colaborativas e quanto suas formas de armazenamento, preservação, gestão e divulgação de conteúdos digitais a exemplo de portais, blogs, museus digitais, redes sociais, jogos virtuais, dados virtuais diversos dentre outros nas esferas de ensino e pesquisa acadêmica.

Abrindo o dossiê, o artigo intitulado NETNOGRAFIA E ESPAÇOS COLABORATIVOS DE ENSINO E APRENDIZAGEM: o caso do blog "estágio II UFPE 2018.2" do curso de letras-português da UFPE de Clecio dos Santos Bunzen Júnior, Alexandre Machado Marques de Souza Sobrinho e Emerson de Brito Sarmento apresentam a netnografia enquanto instrumento metodológico de pesquisa adequado à compressão do uso de blogs enquanto ferramentas 


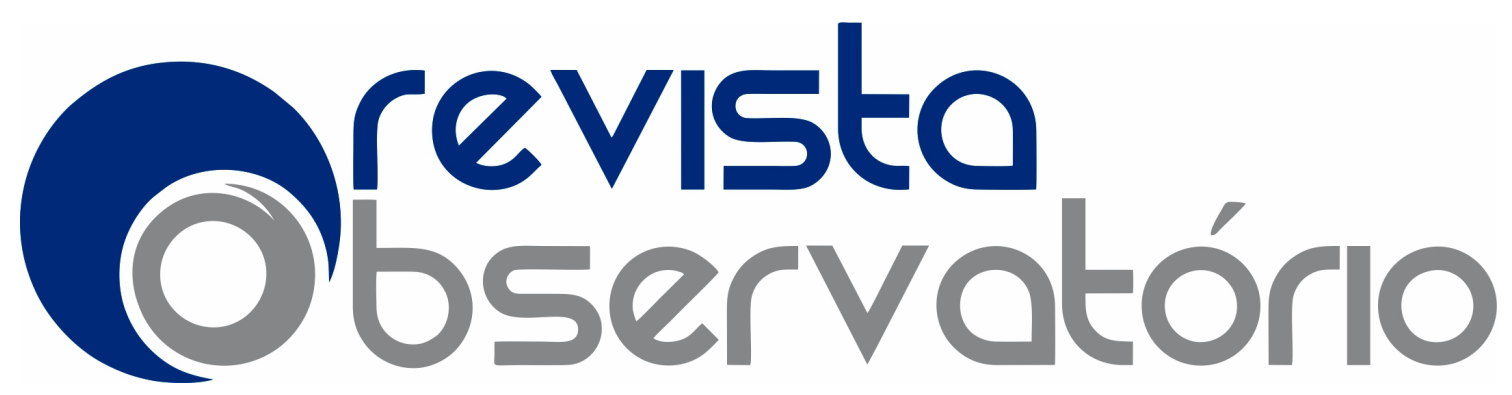

DOI: http://dx.doi.org/10.20873/uft.2447-4266.2019v5n6p26

eficazes à disseminação de conhecimentos e processos de ensino e aprendizagem no campo da educação. Em termos metodológicos, optou-se pela análise do Blogger "Estágio II UFPE 2018.2", desenvolvido no âmbito do componente curricular "Estágio Supervisionado Obrigatório em Língua Portuguesa II", do curso de Letras da UFPE.

No artigo intitulado ABORDAGEM METODOLÓGICA NO JORNALISMO PÓS-INDUSTRIAL: o uso da netnografia em estudo sobre redação virtual, Ivan Bomfim e Larissa Cantuária Lucena analisam a netnografia como método de pesquisa no jornalismo, considerando os estudos a respeito de comunidades e culturas no espaço online. Para tanto, primeiramente, aborda o conceito de humanidades digitais e discute sobre o cenário pós-industrial. Também debate acerca das aproximações e diferenças que permeiam as definições de etnografia e netnografia para, em seguida, elucidar a aplicação metodológica no site amapaense SelesNafes.com.

No artigo intitulado A PESQUISA ETNOGRÁFICA ONLINE EM TEMPOS DE CULTURA DA CONVERGÊNCIA, Jaqueline Gomes de Aguiar discorre sobre algumas dimensões da pesquisa em meios online, considerando as mudanças comunicacionais e sociais desde o surgimento da Internet e das novas interrelações que passaram a se estabelecer entre os sujeitos; os modos de interação humana mediada pelas tecnologias, e a proveniente ressignificação de modos de estar e de viver em um mundo cada vez mais tecnológico e conectado.

No artigo intitulado CURTIR, COMENTAR E COMPARTILHAR: como as seguidoras da Boca Rosa e Niina Secrets interagem nas redes, Thaisa Bueno, Even Grazielly de Sousa Escócio Silva e Lucas Santiago Arraes Reino identificam os motivos que levam as fãs das influenciadoras digitais Boca Rosa e Niina Secrets a curtirem, comentarem e compartilharem suas postagens nas redes sociais. As duas youtubers foram vencedoras do Prêmio Influenciadores Digitais, de 2017, 


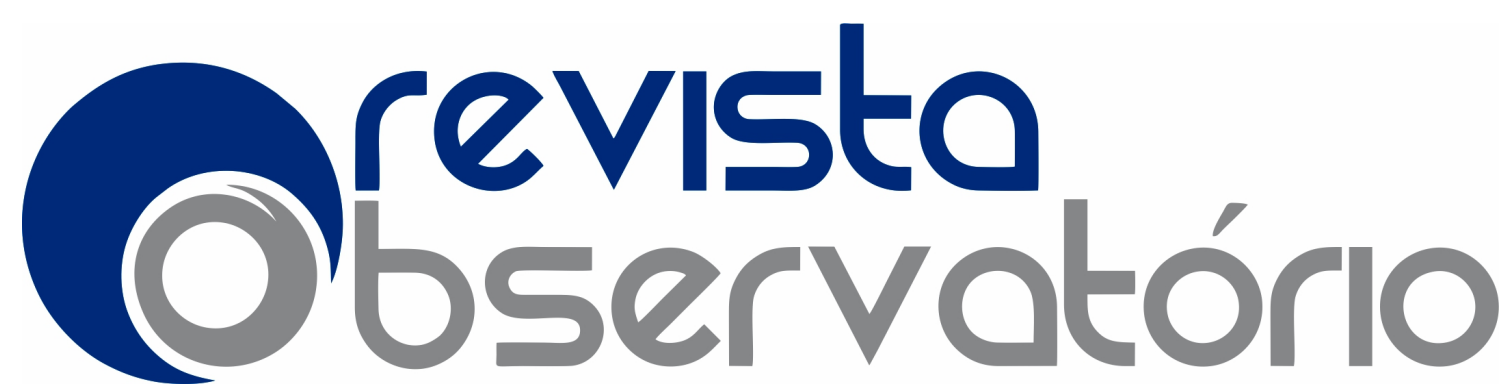

oferecido pela revista Negócios da Comunicação, cujo votação passava pelo voto técnico e popular, nas categorias Moda e Beleza, respectivamente. A escolha da temática se justifica porque curtidas, comentários e compartilhamentos são termômetros da audiência e permitem entender como os seguidores se relacionam com o conteúdo.

No artigo intitulado A SAÚDE COMO PRETEXTO PARA QUEM QUER SER DESEJADO SEXUALMENTE: um estudo etnográfico em perspectiva midiática, Jeferson Bertolini apresenta resultados de estudo sobre a relação entre saúde, tema em voga na TV brasileira, e sexo. Por meio de observação participante com clientes de supermercado e alunos de academia de ginástica de Santa Catarina, descobriu-se que a saúde pode ser pretexto para quem, no fundo, quer ser desejado/a sexualmente; apurou-se ainda que a vontade de ser desejado/a sexualmente é mantida em segredo porque o sexo ainda é influenciado por tabus.

No artigo intitulado A RESPOSTA DOS ESPECTADORES DO YOUTUBE A PROPAGANDAS INTEGRADAS AO CONTEÚDO DE VÍDEOS: um estudo netnográfico, Kathiane Benedetti Corso e Matheus de Mello Barcellos analisam a resposta de usuários do YouTube à existência de propaganda inserida dentro do conteúdo de vídeosPara se chegar a tal objetivo foi realizada uma pesquisa exploratória e qualitativa através do método netnográfico. Como principais resultados foi observado que existem cinco modelos utilizados pelos produtores de conteúdo para a inserção de propagandas no conteúdo de vídeos.

No artigo intitulado INTERATIVIDADE DIGITAL, GESTÃO DE MARCA E CONSTRUÇÃO DA REPUTAÇÃO: O Hotel Alpestre no Tripadvisor, Cristiano Max Pereira Pinheiro, Adriana Stürmer, Débora Wissmann e Heitor Moschen Pedroso analisam as interações digitais do Hotel Alpestre, localizado em Gramado, RS, 


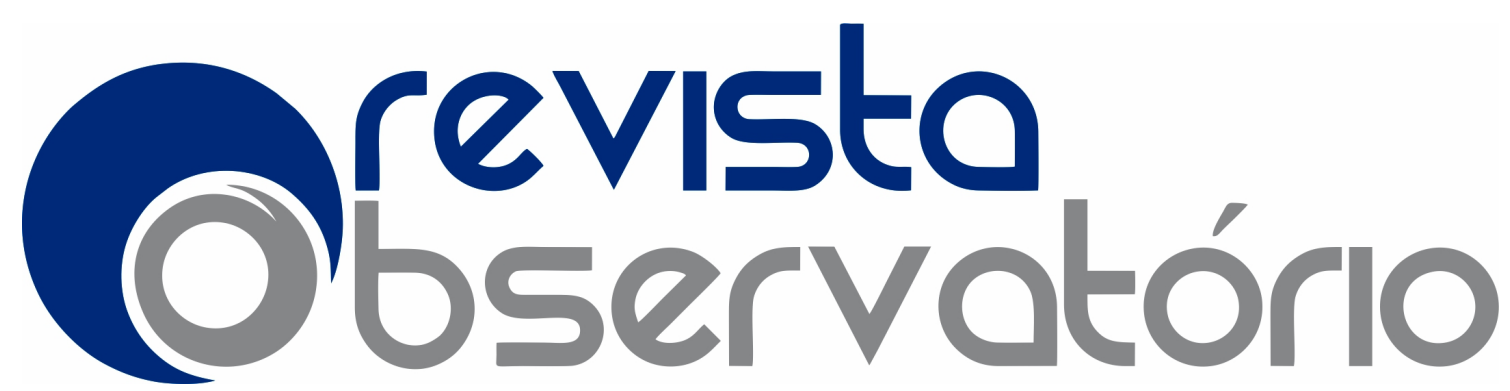

com seus clientes, através do TripAdvisor, como parte de um processo de gestão de marca e de construção de reputação.

No artigo intitulado COMO ESTÃO "NAVEGANDO" NOS CURSOS DE PÓSGRADUAÇÃO EM ADMINISTRAÇÃO?: um estudo sobre o uso da netnografia nas disciplinas de método de pesquisa, Kathiane Benedetti Corso, Rodrigo de Oliveira Estela e Marina Valim Bandeira esclarecem o conceito básico a respeito da Netnografia, bem como demonstrar a utilização do método nos cursos de PósGraduação em Administração no Brasil, tendo como pano de fundo o boom da internet nos últimos anos.

Na seção TEMAS LIVRES, iniciamos com o artigo intitulado FORMAÇÃO INTERDISCIPLINAR NO JORNALISMO: uma experiência de articulação entre as disciplinas de Linguagem de Programação Visual e Oratória, Lucas Santiago Arraes Reino, Thaísa Bueno e Mariana Guedes Conde Falcão apresentam o resultado de uma pesquisa aplicada que interligou as disciplinas de Oratória e Linguagem de Programação Visual no curso de Jornalismo na UFMA de Imperatriz. A proposta foi testar uma didática interdisciplinar e prática com o intuito de promover uma reflexão inicial sobre a formação na área e a viabilidade em incluir nesse processo estudos sobre linguagem de programação por meio da criação de aplicativos.

No artigo intitulado PERCEPÇÕES SOBRE CIBERESPAÇO E TERRITORIALIDADE DIGITAL: estudo exploratório com foco em aspectos socioculturais presentes na deep web e dark web, Cássio Cipriano Nogueira e Braz Batista Vas discutem a internet com foco na Deep Web e na Dark Web. Para os autores, aquilo que muitos conhecem popularmente como Internet, caracteriza-se, socioculturalmente como ciberespaço e possui territorialidade própria, bem como suas próprias práticas culturais, identificadas como cibercultura. Tendo em vista que, para trazer à luz percepções fundamentais 


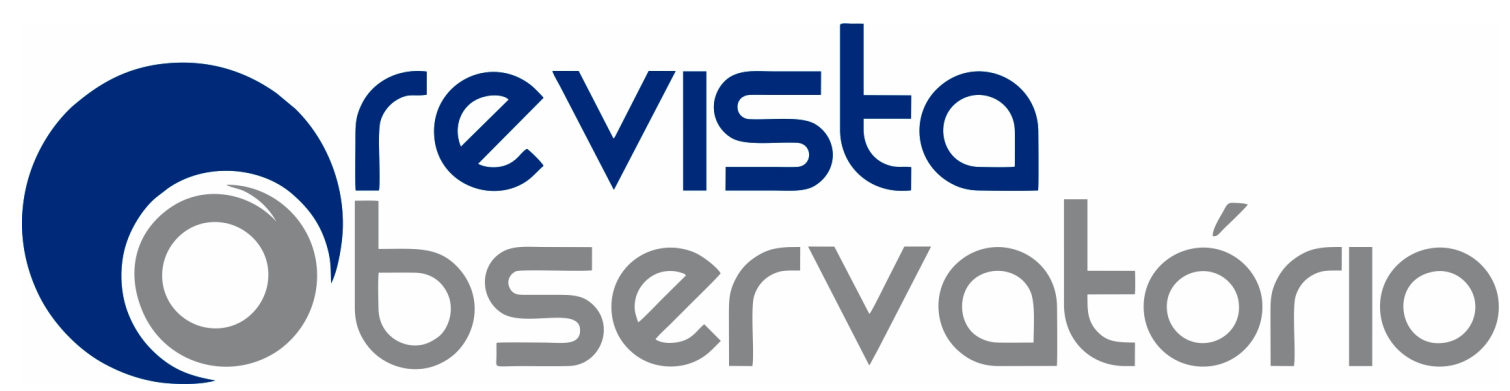

DOI: http://dx.doi.org/10.20873/uft.2447-4266.2019v5n6p26

acerca de determinados territórios faz-se necessário analisá-los sob diferentes óticas, contemplando dimensões tais como a política, a econômica, a social e a cultural, este artigo tem como objetivo a realização de um estudo exploratório sobre a territorialidade digital do ciberespaço, por meio de pesquisa bibliográfica e análise de conteúdo, de modo a examinar e destacar aspectos socioculturais a partir das alterações promovidas pela Web 2.0 e percepções sobre as frações do ciberespaço designadas genericamente de Deep Web Dark Web.

No artigo intitulado APP-LEARNING: contribuições do Kahoot no Ensino de Jornalismo, Jean Carlos da Silva Monteiro, Sannya Fernanda Nunes Rodrigues e Sheila Cristina Birino Pinheiro tratam das contribuições do aplicativo Kahoot no ensino de Jornalismo da Faculdade Estácio de São Luís. Analisam a inserção e uso do Kahoot para avaliar os conhecimentos dos alunos na disciplina Práticas de Jornalismo Multimídia em tempo real.

No artigo intitulado 80 ANOS NA SALA DE REDAÇÃO: Lois e Clark e o estereótipo do Jornalista, Junno Sena Maia e Maristela Fittipaldi Vianna da Silva procuram analisar a criação dessa persona e como isso afeta a sociedade e o trabalho do jornalista. Tal pesquisa permitiu chegar à conclusão de que produções assim, acima de simples entretenimento, servem para conscientizar o público, elevar o debate e trazer um senso crítico a profissão do jornalista.

No artigo intitulado O APAGAMENTO DO SENTIDO JORNALÍSTICO DE CONSTRUÇÃO COLETIVA PELA INDIVIDUAÇÃO: "Obrigado por suas informações!", Sean Hagen discute a personalização dos jornalistas nas entradas "ao vivo" em oposição ao sentido de jornalismo como construção coletiva está passando por um processo de naturalização nos telejornais da Rede Globo. Esta é uma postura conflitante com as finalidades do campo: amplifica o poder político creditado ao jornalismo ao personalizar, via enunciação, ações cotidianas intrínsecas da profissão; isso intensifica a credibilidade de empresas, jornais e 


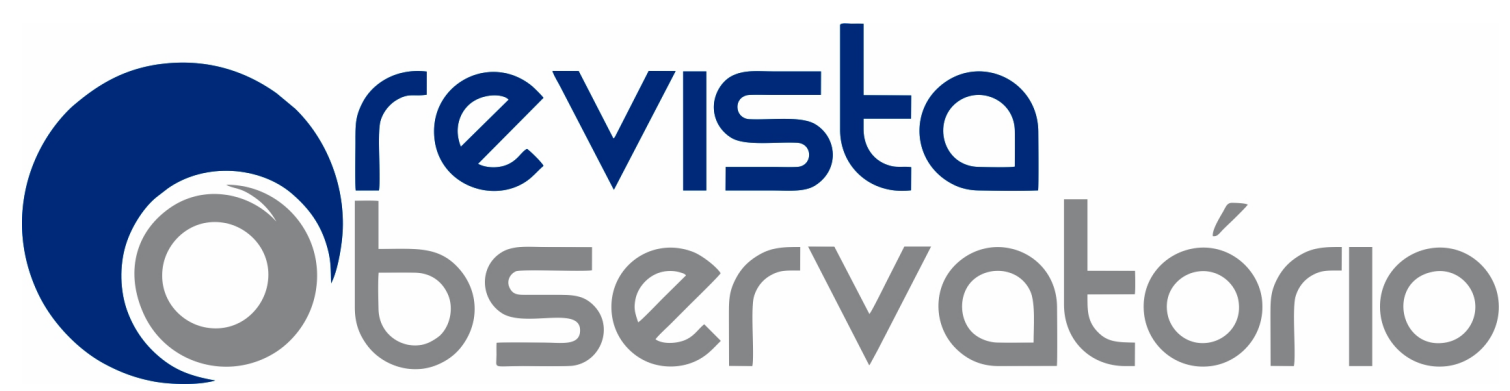

jornalistas. Os pronomes possessivos, as conjugações verbais na primeira pessoa do singular e o adjetivo "obrigado" são as principais manifestações dessa prática, que vem crescendo nos últimos anos. Para desvelar esses sentidos, a amostragem qualitativa recaiu sobre o Jornal Hoje, Jornal Nacional e Jornal da Globo.

No artigo intitulado A REPRESENTAÇÃO DA AMAZÔNIA BRASILEIRA NA SÉRIE "AMAZÔNIA SOCIEDADE ANÔNIMA (S/A)", Fábio Borges, Domingos de Almeida e Julie Andrea Lemos Bohórquez analisam a representação da Amazônia brasileira na série "Amazônia Sociedade Anônima (S/A)", exibida em 2015 pelo programa Fantástico da TV Globo. Na fundamentação teórica recorremos a Benchimol (2009), Borges (2011), Martino (2007) e outros. Utilizam como metodologia Pesquisa Bibliográfica, Documental e Análise do Discurso (AD) de linha francesa.

No artigo intitulado RELACIONAMENTO ENTRE FONTES E JORNALISTAS: estudo de caso de uma universidade pública, Adriano Charles Silva Cruz e Marina Ferreira Gadelha discutem a relação das fontes da Universidade Federal do Rio Grande do Norte com jornalistas da cidade de Natal-RN. Após uma revisão de literatura, foi aplicado um questionário como instrumento de coleta de dados. $\mathrm{O}$ universo da pesquisa é composto por 74 jornalistas de quatro empresas de comunicação da capital potiguar. O estudo resultou em um mapeamento das principais características, lacunas e potencialidades dessas fontes, segundo a ótica dos respondentes.

No artigo intitulado INFLUÊNCIA MIDIÁTICA NA CONDENAÇÃO POPULAR ANTECIPADA, Érika Souza, Igor Andrade Barbosa e Valdirene Cássia da Silva relacionam a mídia social e sua intervenção na opinião do povo brasileiro, especialmente em relação aos casos que causam notória comoção pública. Foram abordadas questões como a liberdade de expressão, a evolução histórica da 


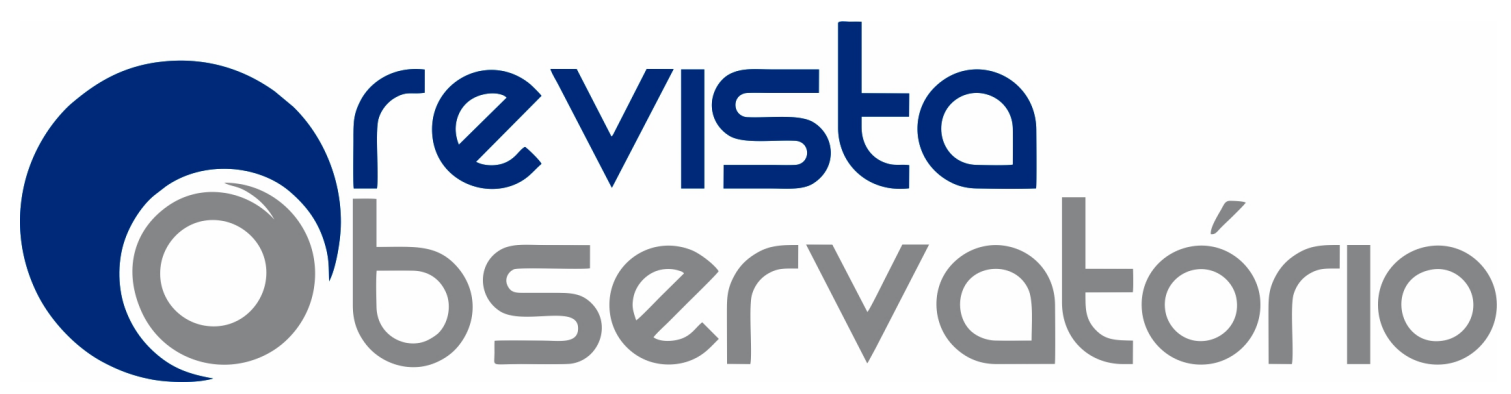

mídia, o papel social da imprensa e da notícia, bem como, o direito ao esquecimento.

No artigo intitulado CARRY FIRE: um estudo de recepção das críticas musicais ao disco de Robert Plant, Fábio Cruz e Arthur Freire Simões Pires realizam um estudo voltado à compreensão de como receptores, que cursaram uma disciplina universitária, que une comunicação com o gênero musical rock, compreendem as críticas musicais, entendidas como um subgênero do jornalismo cultural (PIZA, 2013). Sob preceitos de Kellner (2001) e Orozco Gómez (2000), analisamos o debate com o grupo focal acerca de dois textos produzidos pelos veículos The Guardian (Inglaterra) e Omelete (Brasil). Entendemos que os textos reforçam estereótipos, fator este que corrobora um posicionamento contrário por parte dos receptores em relação ao conteúdo dos textos selecionados.

No artigo intitulado A EDUCAÇÃO DE IDOSOS NA VEJA E NA FOLHA DE SÃO PAULO: dados para uma análise crítica, Patrícia Mattos Amato Rodrigues, Simone Caldas Tavares Mafra e Eveline Torres Pereira investigam a educação de idosos enquanto notícia na revista Veja e no jornal Folha de São Paulo, pois se acredita no poder desses veículos de mídia na construção dos valores e necessidades da sociedade brasileira. Trata-se de pesquisa descritiva, tendo a coleta dos dados suporte bibliográfico e documental.

No artigo intitulado TECNOLOGIAS DIGITAIS NA EDUCAÇÃO TOCANTINENSE: uma análise da contribuição para o professor, Maria José de Pinho e Deusirene Magalhães de Araújo analisam contribuições das tecnologias digitais para o professor tocantinense. Destaca as tecnologias na educação do Tocantins e a formação do professor como espaço de reflexão e autonomia docente. 


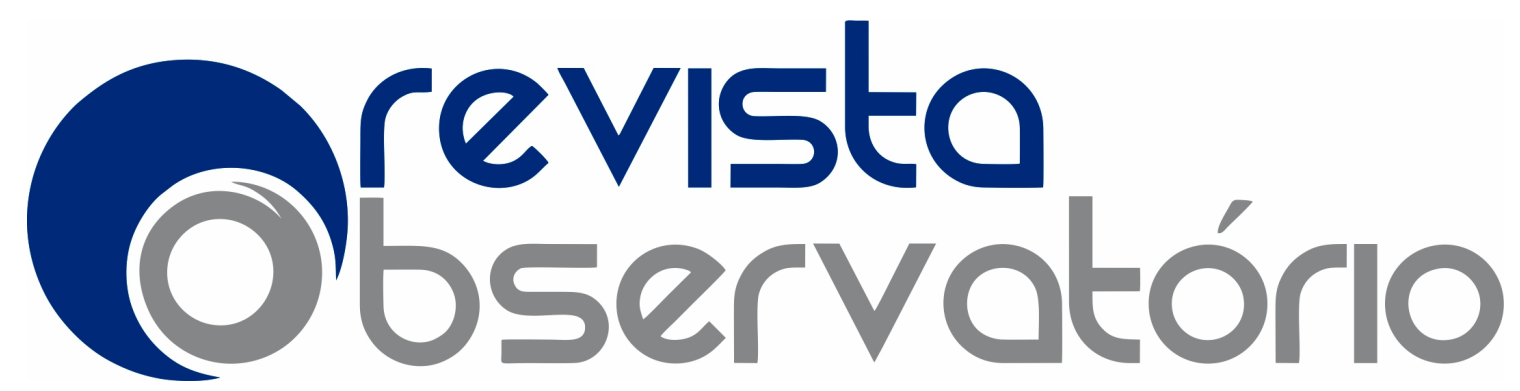

ISSN n² 2447-4266

Vol. 5, n. 6, Outubro-Dezembro. 2019

DOI: http://dx.doi.org/10.20873/uft.2447-4266.2019v5n6p26

No artigo intitulado APRENDIZAGEM ATIVA: reflexão sobre o indicador "metodologia" na avaliação de cursos, Tânia Suely Azevedo Brasileiro e Enedina Betânia Leite de Lucena Pires Nunes compreendem a relação entre a aprendizagem ativa e o Indicador "Metodologia" do Instrumento de Avaliação de Cursos de Graduação, do MEC. Procuram desmistificar uma prática baseada em palestras ajudando a criar uma linguagem do ensino como uma forma ética de expressão, favorecendo o estabelecimento de uma aprendizagem ativa dentro da universidade em que foi aplicada uma ação metodológica de intervenção teórico-prática em sala de aula com a adoção de estratégias em técnicas de problema e confronto.

No artigo intitulado TECNOLOGIAS DIGITAIS E ENSINO DE INGLÊS: uma proposta de escrita colaborativa e produção de vídeo, Keila Mendes Santos e Cleide Jane de Sa Araújo Costa analisam contribuições da utilização das TDIC no processo de desenvolvimento das habilidades de speaking e writting em aprendizes de inglês, partindo da proposta de produção de um vídeo e da escrita colaborativa de um e-book. Trata-se de uma pesquisa qualitativa, configurada como estudo de caso, que teve como participantes 6 licenciandos em língua inglesa (LI).

No artigo intitulado FORMAÇÃO DOCENTE: uso das tecnologias como ferramentas de interatividade no processo de ensino, José Damião Trindade Rocha e Clerislene da Rocha Morais Nogueira analisam a formação de professores e uso das tecnologias como ferramentas interativas no processo de ensino e aprendizagem dos alunos. A pesquisa constituiu-se num objeto de estudo, visando abordar a formação, o ensino e uso das tecnologias.

No artigo intitulado ENFERMAGEM NA PROMOÇÃO DA SUSTENTABILIDADE AMBIENTAL: uma revisão integrativa, Tailana Santana Alves Leite, José Lauro Martins, Nayana Barros de Assunção, Amanda Andrade de 


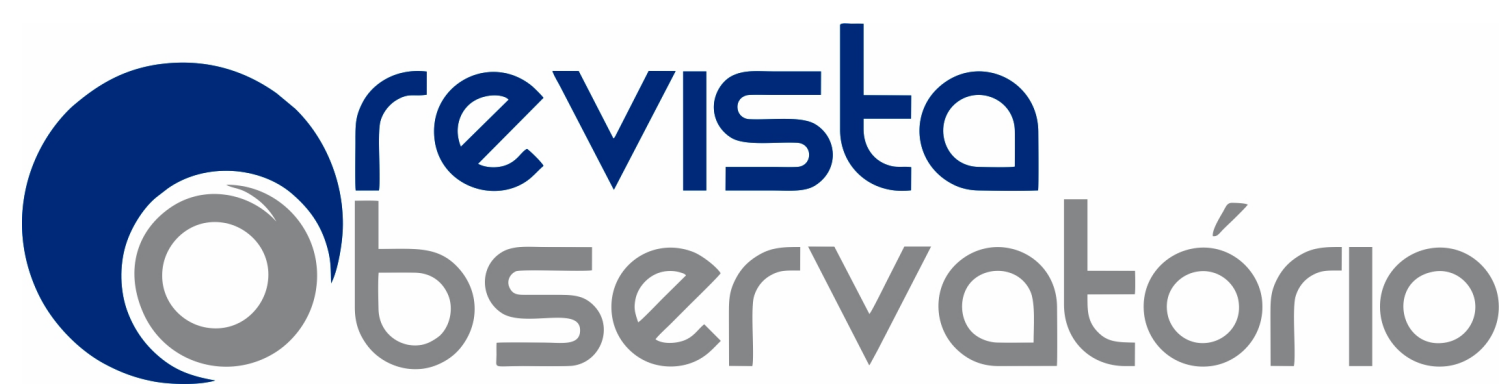

Almeida, Fernando Dias da Silva, José Mateus de Almeida Costa e Sandreane Alves dos Santos focam a atuação do profissional de enfermagem em promover sustentabilidade ambiental. Utilizando-se de uma pesquisa com base na revisão de literatura integrativa, a discursão contou com 9 autorias e foi organizada ora pela concordância dos autores, ora pela discrepância entre as ideias. Ademais se construiu uma ideia a partir das publicações, em sua grande parte pesquisas de campo e atividades que envolveram ações junto a comunidade. A partir dos estudos analisados, notou-se que o serviço da enfermagem inerente à saúde ambiental atribui-se, imprescindivelmente, as ações educativas.

No artigo intitulado A BUSCA POR PADRÕES NA RESOLUÇÃO DE PROBLEMAS MATEMÁTICOS NOS ANOS FINAIS DO ENSINO FUNDAMENTAL, Wanderson Santos do Nascimento e César de Oliveira Zica propoem a importância da busca por padrões matemáticos como ferramenta auxiliadora na resolução de exercícios nas series finais do ensino fundamental, mostrando que estes podem agir como um pilar para uma educação eficaz e duradoura. Foi realizado um estudo bibliográfico com diferentes autores, no intuito de trazer clareza sobre o tema, buscando uma fundamentação teórica relacionada com a importância do mesmo para um ensino aprendizagem significativo.

No artigo intitulado O JORNALISMO ECONÔMICO E AS VOZES QUE FALARAM NOS JORNAIS NOS ANOS DE DEBATE DAS REFORMAS DA PREVIDÊNCIA, Taianne Santos Moreira de Souza e Antônio José Pedroso Neto analisam como os jornais Folha de São Paulo, O Globo, O Estado de São Paulo e o Valor Econômico abordaram a Previdência. Considerou-se dois modelos: Capitalização e Repartição simples. Buscou-se perceber se esses veículos, privilegiaram um modelo em detrimento a outro.

No artigo intitulado REVISTA TRAVEL IN BRAZIL (1941-42): música, rendas e bonecas artesanais, por Mário de Andrade, Nóbrega da Cunha e Cecília 


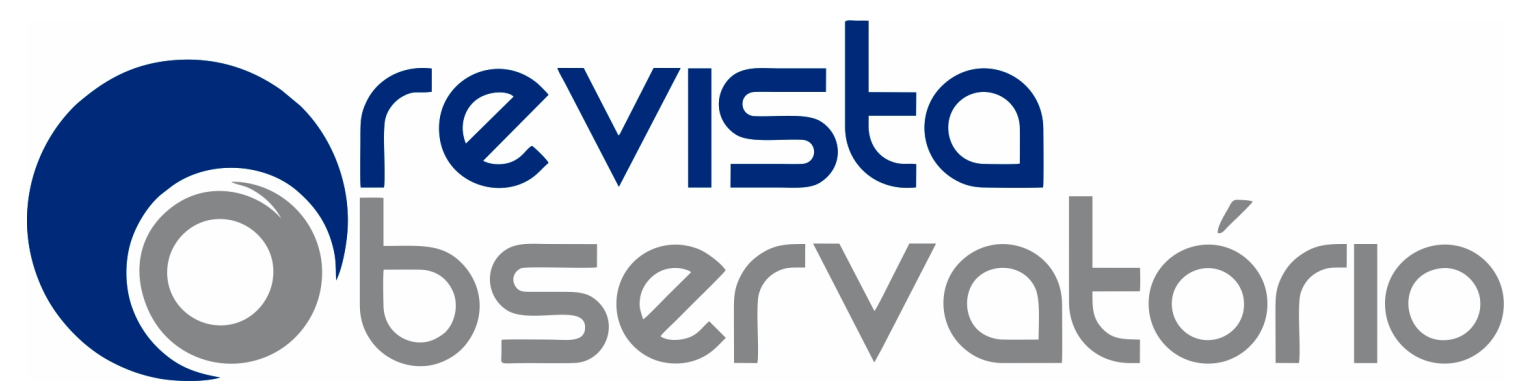

ISSN n² 2447-4266

Vol. 5, n. 6, Outubro-Dezembro. 2019

DOI: http://dx.doi.org/10.20873/uft.2447-4266.2019v5n6p26

Meireles, Luis Antonio Contatori Romano e Cristyane de Souza Gomes Santana estudam a relação entre as imagens e o conteúdo verbal dos textos "Música Brasileira", "Rendas Artesanais Brasileiras" e "Bonecas Brasileiras", escritos respectivamente por Mário de Andrade, Nóbrega da Cunha e, provavelmente, Cecília Meireles. Esses textos foram publicados na revista Travel in Brazil, em 1941-1942, que foi editada por Cecília Meireles e financiada pelo Departamento de Imprensa e Propaganda (DIP) do Governo de Vargas, que era responsável por divulgar a cultura brasileira no exterior visando estabelecer um fluxo de turistas estadunidenses para o Brasil.

No artigo intitulado CULTURA DOS MEMES NO AMBIENTE CONECTIVO: identidades e criação coletiva, Soraya Maria Ferreira Vieira e Luiza de Mello Stefano propõem uma análise que compreende a autorrepresentação no ambiente conectivo através da criação coletiva de memes como vetor que opera na construção de identidades. A partir do engajamento dos fãs do programa de reality show Big Brother Brasil, observam os processos cognitivos, estéticos e linguísticos e as práticas de ressignificação de mensagens na produção e consumo de memes.

No artigo intitulado A AULA DE INGLÊS E O DESMONTE DA EDUCAÇÃO COMO PRÁXIS POLÍTICA: Um projeto de alienação do sujeito social, Davi Silva Gonçalves reflete acerca de questões educacionais em paralelo com a práxis social. Mais especificamente, a ideia é discutir as características e implicações da realidade e prática social dos alunos da escola pública levando em consideração anseios contemporâneos pautados no tema.

No artigo intitulado O MAL EM APOCALÍPTICOS E O BEM EM INTEGRADOS, Gabriel Sausen Feil, Simone Munir Dahleh e Júlia Rocha Paz focam no tempo como o tema principal do presente trabalho, que traz os conceitos de Mal e Bem, de Georges Bataille (1989), e as concepções de cultura pelo entendimento dos 


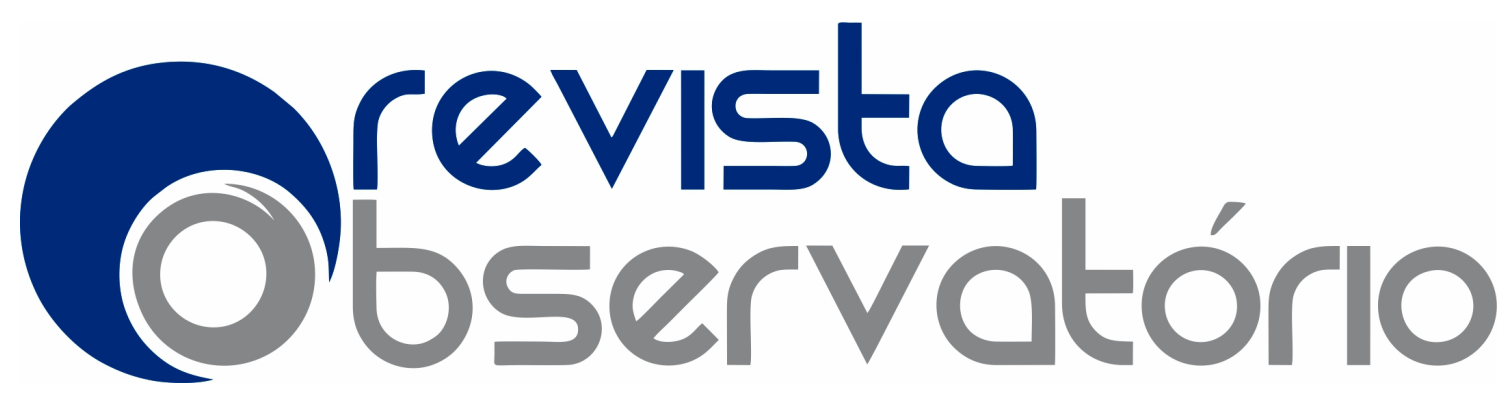

apocalípticos e integrados, de Umberto Eco (2006), com o intuito de aproximar tais conceitos por conta de suas possibilidades de relações com o tempo.

No artigo intitulado A ADAPTAÇÃO E INTEGRAÇÃO DAS AÇÕES DE MARKETING ON-LINE E OFF-LINE DO MONET PLAZA SHOPPING EM SANTA MARIA (RS), Taís Steffenello Ghisleni e Dafne de Mello Lopes verificam como o Monet Plaza Shopping tem realizado, através das ações de marketing, a adaptação e integração on-line e off-line para que cumpra o papel do marketing institucional através do caminho realizado pelo consumidor. Para a realização da análise, os autores realizaram uma pesquisa de natureza qualitativa, exploratória e descritiva, através da observação e verificação do conteúdo das redes sociais do empreendimento e das ações realizadas diretamente no local.

No artigo intitulado VALIDAÇÃO DE VÍDEO LÚDICO: educação em saúde de idosos hipertensos para a promoção do uso correto e seguro de medicamentos e conhecimento sobre sua doença, Carolina Galgane Lage Miranda, José Lamartine Soares-Sobrinho e Mauro Silveira de Castro discutem a utilização do vídeo "Uma história ImPRESSÃOnante" como ferramenta de educação em saúde para idosos hipertensos, a fim de determinar o ganho de conhecimento entre grupo controle (recebeu palestra tradicional) e grupo intervenção (assistiu ao vídeo). O vídeo produzido teve o objetivo de desenvolver o uso correto e seguro de medicamentos e promover o conhecimento sobre hipertensão e práticas não farmacológicas para tratamento da doença.

No artigo intitulado AS DIFICULDADES DE LICENCIANDOS COM O USO DE MATERIAIS AUTORAIS DIGITAIS EDUCACIONAIS, Luciana de Lima analisa quais são as dificuldades que os licenciandos da disciplina Tecnodocência ofertada no apresentam em relação à utilização de Materiais Autorais Digitais Educacionais (MADEs). A pesquisa qualitativa de caráter exploratório, investiga cinco grupos 


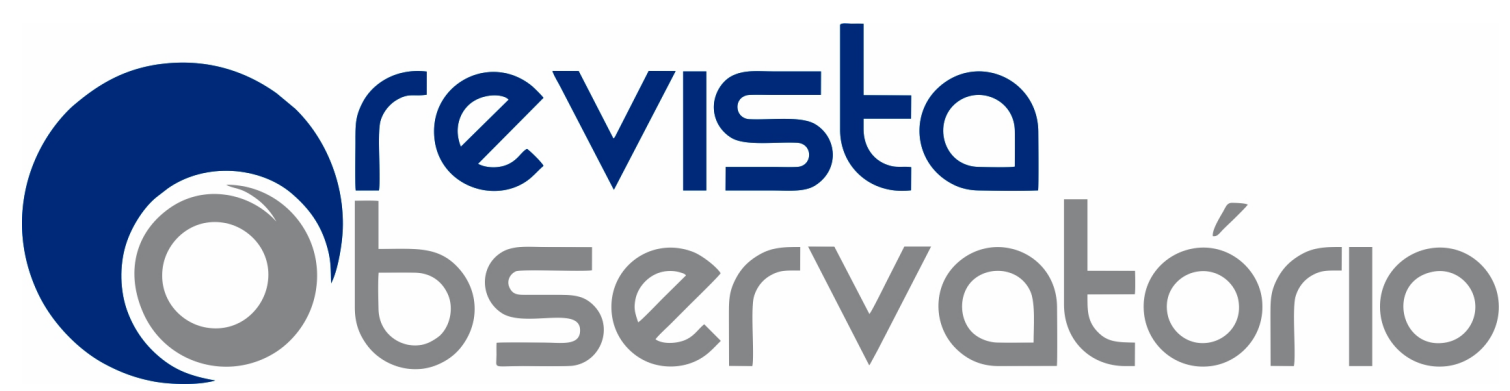

ISSN n² 2447-4266

Vol. 5, n. 6, Outubro-Dezembro. 2019

DOI: http://dx.doi.org/10.20873/uft.2447-4266.2019v5n6p26

interdisciplinares formados por licenciandos de diferentes áreas do conhecimento.

No artigo intitulado TELE-SOLIDARIEDADE EM FAMÍLIA NAS TARDES DE SÁBADO DA TV GLOBO: um estudo sobre o Caldeirão do Huck e o Estrelas Solidárias, Valquiria Aparecida Kneipp e Renato Ferreira de Moraes abordam as características do discurso de solidariedade intrínseco à linguagem dos programas "Estrelas Solidárias" e "Caldeirão do Huck", ambos exibidos aos sábados na Rede Globo de Televisão em rede nacional. A hipótese é que o grotesco, codificado na carência das classes menos favorecidas ou em casos individuais de carência afetiva ou material, é a principal narrativa desse tipo de articulação, em que informação e entretenimento se fundem.

No artigo intitulado A HISTORIA DA ASSISTÊNCIA ESTUDANTIL NO ENSINO SUPERIOR BRASILEIRO: programa nacional de assistência estudantil e o aumento das classes "D" e "E" nas universidade federais, Paulo Fernando de Melo Martins, Eder Gama da Silva e Nathanni Marrelli Matos Mauricio demonstram quais os meios que vem sendo empregados para a efetiva garantia desse direito aos estudantes das universidades públicas brasileiras, bem como demonstrar o aumento e permanência dos estudantes das classes "D e E" nessas instituições.

No artigo intitulado A PEDAGOGIA DO CORPO MÁQUINA NA TELA DA TV, Jeferson Bertolini apresenta resultados de pesquisa sobre os recursos pedagógicos usados pelo programa Bem Estar, da Rede Globo, para ensinar o público a cuidar no corpo. O texto usa análise de conteúdo. Adota o conceito de biopoder para pensar o corpo no âmbito político, não estético. O manuscrito recorre a técnica interdisciplinar para associar temas das Ciências Humanas à Comunicação Social.

No artigo intitulado CONSTRUÇÃO COMPARTILHADA DE VÍDEO PARA EDUCAÇÃO DE IDOSOS HIPERTENSOS, Carolina Lage Miranda Galgane, Mauro 


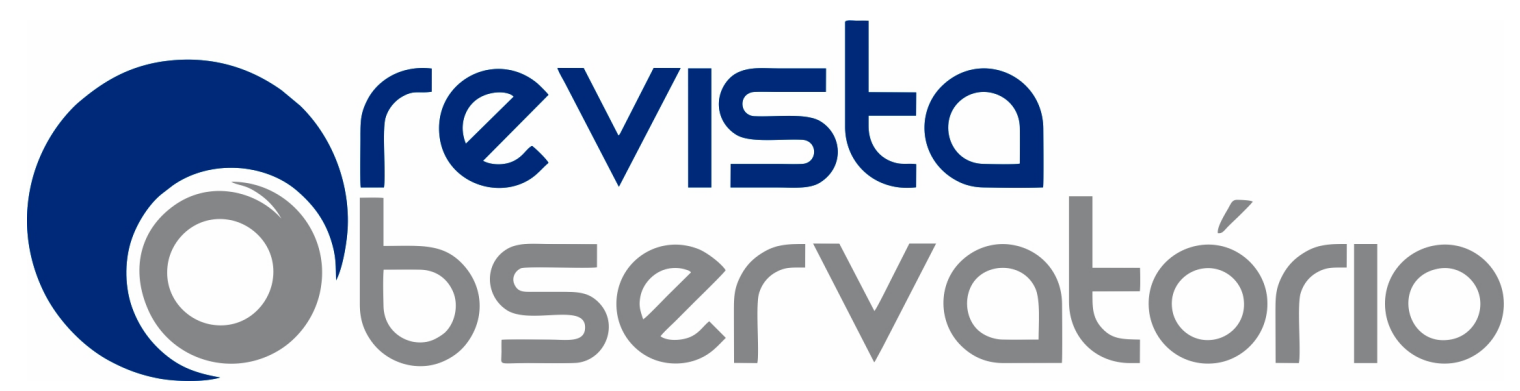

ISSN n² 2447-4266

Vol. 5, n. 6, Outubro-Dezembro. 2019

DOI: http://dx.doi.org/10.20873/uft.2447-4266.2019v5n6p26

Silveira de Castro e José Lamartine Soares-Sobrinho descrevem a experiência sobre elaboração de material educativo, formato de vídeo artístico criado coletivamente por pesquisadores e idosos hipertensos, como estratégia para obtenção de atitude reflexiva, participativa e autônoma sobre sua doença, cuidado de si e uso correto e seguro de medicamentos.

Na Seção RESENHAS, a primeira intitulada A DEMOCRACIA SEM FIM, de Alexandre José Pierini traz uma visão sobre o livro LEVISTSKY \& ZIBLATT. Como as democracias morrem. Rio de Janeiro: Zahar, 2018. A segunda intitulada POR QUE O EMPODERAMENTO DAS MULHERES NEGRAS CAUSA MEDO?, de Débora Bianco Lima Garbi que traz uma reflexão sobre o livro de RIBEIRO, Djamila. Quem tem medo do feminismo negro? São Paulo: Companhia das Letras, 2018. E finalizando as resenhas, o texto A HISTÓRIA DA EDUCAÇÃO ENTRE FRONTEIRAS:HORIZONTES E PERSPECTIVAS DA PESQUISA EM EDUCAÇÃO de Vinicius Kapicius Plessim e Fagno da Silva Soares que trazem a resenha do livro DE SÁ, Elizabeth Figueiredo; SIMÕES, Regina Helena Silva; NETO, Wenceslau Gonçalves (Orgs.). Circuitos e fronteiras da história da educação. Vitória: EDUFES, 2015.

Na seção ENTREVISTA, o texto intitulado POR UMA AVALIAÇÃO DA APRENDIZAGEM COMO ATO AMOROSO: 50 anos da oficina pedagógica de Cipriano Luckesi, realizada por Fagno da Silva Soares e Pricila Linhares Feitosa. Trata-se de uma entrevista realizada durante o X Encontro Técnico-Pedagógico IFMA/Campus Açailândia em 23 de janeiro de 2019, com o teórico da educação Cipriano Carlos Luckesi, professor aposentado da Faculdade de Filosofia e do Programa de Pós-Graduação em Educação da Faculdade de Educação da Universidade Federal da Bahia (UFBA).

E finalizando nosso número, na seção Visualidades, a produção intitulada A MORTE DA NARRATIVA E A NARRATIVA DA MORTE: uma conexão com Walter 


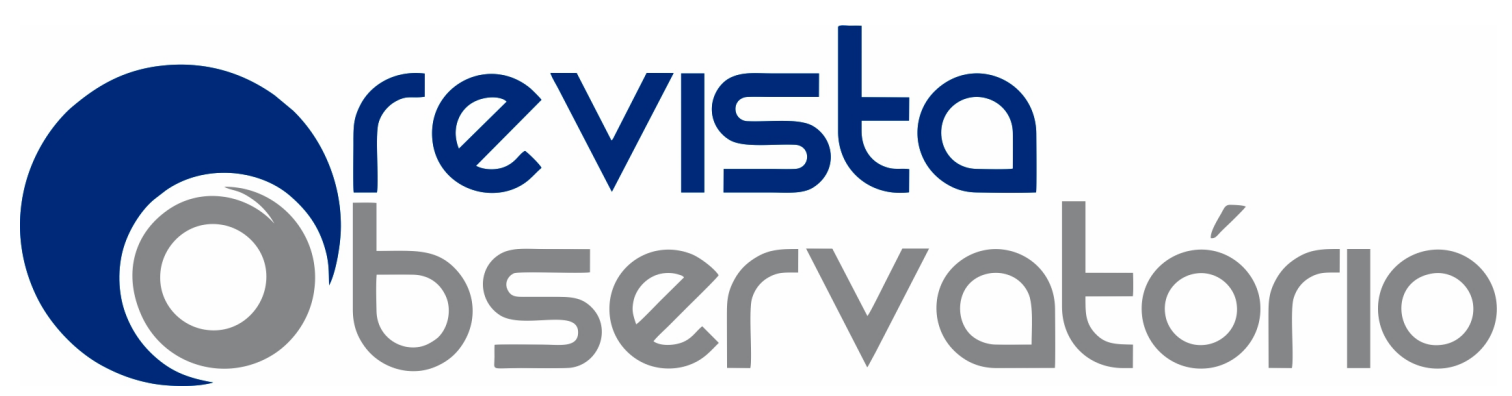

DOI: http://dx.doi.org/10.20873/uft.2447-4266.2019v5n6p26

Benjamin, de Ramiro Barbosa Xavier e Amanda M. P. Leite. Os autores buscam provocar uma reflexão com base em dois ensaios do escritor Walter Benjamin (1892-1940) envolvendo-os com o universo experienciado pela população LGBTI+, de maneira a compreender como as narrativas desta população são construídas e apresentadas nos ambientes midiáticos.

Sejam todos/as bem-vindos/as as temáticas deste número! Leia, compartilhe e indique a leitura dos artigos produzidos no n. 6 de 2019 da Revista Observatório.

Palmas, TO, Imperatriz-MA e Tupã-SP, outubro de 2019.

Editores convidados/ Guest Editors/ Editores invitados

Prof. Dr. Fagno da Silva Soares (CLIO \& MNEMÓSINE/IFMA e Núcleo de Estudos em História Oral - NEHO/USP), Brasil.

Prof. Dr. Jesus Marmanillo Pereira (Laboratório de Estudos e Pesquisa sobre Cidades e Imagens - LAEPCI/UFMA), Brasil.

Editor Geral / Chief Editor / Editor general Prof. Dr. Nelson Russo de Moraes, Universidade Estadual Paulista Júlio de Mesquita Filho (UNESP), Brasil.

Prof. Dr. Francisco Gilson Rebouças Porto Junior, Universidade Federal do Tocantins (UFT), Brasil. 


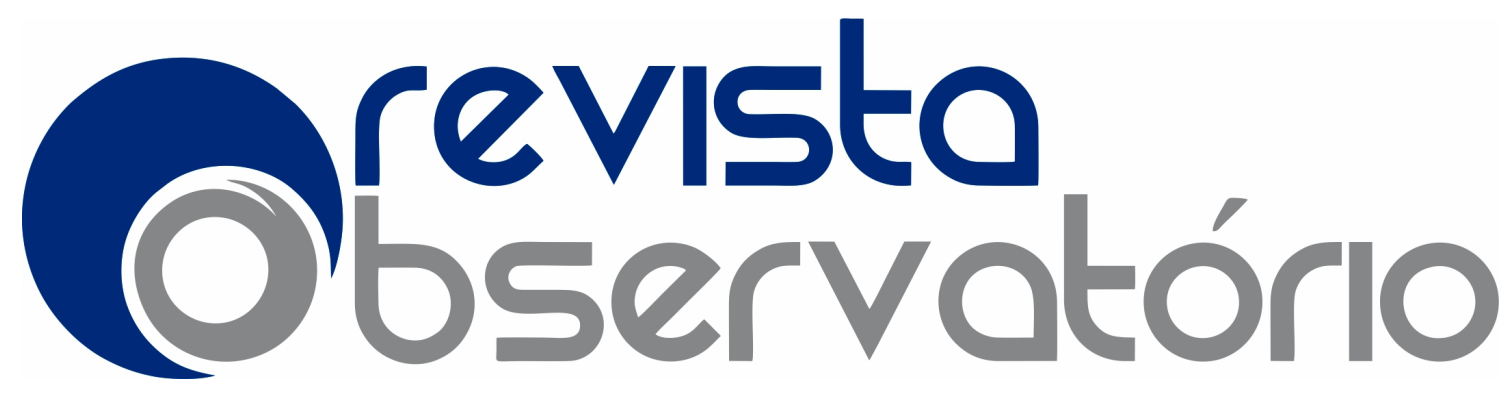

ISSN n² 2447-4266

Vol. 5, n. 6, Outubro-Dezembro. 2019

DOI: http://dx.doi.org/10.20873/uft.2447-4266.2019v5n6p26

\section{Referências}

AGUIAR, J. G. DE. A PESQUISA ETNOGRÁFICA ONLINE EM TEMPOS DE CULTURA DA CONVERGÊNCIA. Revista Observatório, v. 5, n. 6, p. 109-131, 1 out. 2019.

ALMEIDA, D. A.; BORGES, F.; BOHÓRQUEZ, J. A. L. A REPRESENTAÇÃO DA AMAZÔNIA BRASILEIRA NA SÉRIE "AMAZÔNIA SOCIEDADE ANÔNIMA (S/A)". Revista Observatório, v. 5, n. 6, p. 380-403, 1 out. 2019.

AZEVEDO BRASILEIRO, T. S.; NUNES, E. B. B. L. DE L. P. APRENDIZAGEM ATIVA: reflexão sobre o indicador "metodologia" na avaliação de cursos. Revista Observatório, v. 5, n. 6, p. 529-546, 1 out. 2019.

BERNARDO, C. H. C.; BRAGA JÚNIOR, S. S.; MARQUES, M. D.; GOMES, S. C. V.; QUEIROZ, T. R. Percepção dos produtores rurais de Tupã, SP, sobre o processo de comunicação para execução da logística reversa de embalagens de agrotóxicos. Revista Observatório, v. 1, n. 3, p. 242-270, 26 dez. 2015.

BERTOLINI, J. A PEDAGOGIA DO CORPO MÁQUINA NA TELA DA TV. Revista Observatório, v. 5, n. 6, p. 912-932, 1 out. 2019.

BERTOLINI, J. A SAÚDE COMO PRETEXTO PARA QUEM QUER SER DESEJADO SEXUALMENTE: um estudo etnográfico em perspectiva midiática. Revista Observatório, v. 5, n. 6, p. 152-170, 1 out. 2019.

BOMFIM, I.; LUCENA, L. C. ABORDAGEM METODOLÓGICA NO JORNALISMO PÓSINDUSTRIAL: O uso da netnografia em estudo sobre redação virtual. Revista Observatório, v. 5, n. 6, p. 75-108, 1 out. 2019.

BUENO, T. C.; REINO, L. S. A. ENTRE A TABLOIDIZAÇÃO E O TEASER PUBLICITÁRIO: uma análise dos títulos caça-cliques. Revista Observatório, v. 4, n. 3, p. 675-707, 29 abr. 2018.

BUENO, T.; DE SOUSA ESCÓCIO SILVA, E. G.; REINO, L. S. A. CURTIR, COMENTAR E COMPARTILHAR: como as seguidoras da Boca Rosa e Niina Secrets interagem nas redes. Revista Observatório, v. 5, n. 6, p. 132-151, 1 out. 2019.

BUNZEN JÚNIOR, C. DOS S.; MARQUES DE SOUZA SOBRINHO, A. M.; SARMENTO, E. DE B. NETNOGRAFIA E ESPAÇOS COLABORATIVOS DE ENSINO E APRENDIZAGEM: o caso do blog "estágio II UFPE 2018.2" do curso de letrasportuguês da UFPE. Revista Observatório, v. 5, n. 6, p. 46-74, 1 out. 2019. 


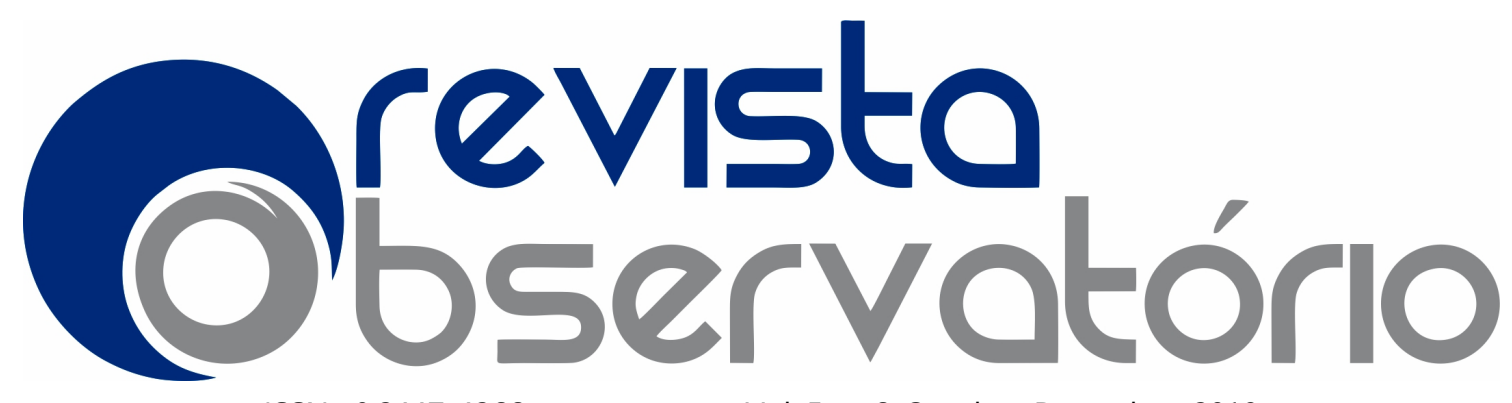

ISSN n² 2447-4266

Vol. 5, n. 6, Outubro-Dezembro. 2019

DOI: http://dx.doi.org/10.20873/uft.2447-4266.2019v5n6p26

CHIECHER, A. C.; FICCO, C. R.; PAOLONI, P. V.; GARCÍA, G. A. ¿Qué mueve a los estudiantes exitosos? Metas y motivaciones de universitarios en las modalidades presencial y distancia. Revista Observatório, v. 2, n. 2, p. 301-326, 30 maio 2016. CONTATORI ROMANO, L. A.; DE SOUZA GOMES SANTANA, C. REVISTA TRAVEL IN BRAZIL (1941-42): música, rendas e bonecas artesanais, por Mário de Andrade, Nóbrega da Cunha e Cecília Meireles. Revista Observatório, v. 5, n. 6, p. 668-699, 1 out. 2019.

CORSO, K. B.; BARCELLOS, M. DE M. A RESPOSTA DOS ESPECTADORES DO YOUTUBE A PROPAGANDAS INTEGRADAS AO CONTEÚDO DE VÍDEOS: Um estudo netnográfico. Revista Observatório, v. 5, n. 6, p. 171-196, 1 out. 2019.

CORSO, K. B.; ESTELA, R. DE O.; BANDEIRA, M. V. COMO ESTÃO "NAVEGANDO" NOS CURSOS DE PÓS-GRADUAÇÃO EM ADMINISTRAÇÃO?: um estudo sobre o uso da netnografia nas disciplinas de método de pesquisa. Revista Observatório, v. 5, n. 6, p. 232-248, 1 out. 2019.

CRUZ, F.; SIMÕES PIRES, A. F. CARRY FIRE: um estudo de recepção das críticas musicais ao disco de Robert Plant. Revista Observatório, v. 5, n. 6, p. 453-472, 1 out. 2019.

ELHAJJI, M.; ESCUDERO, C. WEBDIÁSPORA: Migrações, TICS e memória coletiva. Revista Observatório, v. 2, n. 5, p. 334-363, 25 dez. 2016.

FEIL, G. S.; DAHLEH, S. M.; PAZ, J. R. O MAL EM APOCALÍPTICOS E O BEM EM INTEGRADOS . Revista Observatório, v. 5, n. 6, p. 753-785, 1 out. 2019.

GARBI, D. B. L. POR QUE O EMPODERAMENTO DAS MULHERES NEGRAS CAUSA MEDO?. Revista Observatório, v. 5, n. 6, p. 954-958, 1 out. 2019.

GHISLENI, T. S.; LOPES, D. DE M. A ADAPTAÇÃO E INTEGRAÇÃO DAS AÇÕES DE MARKETING ON-LINE E OFF-LINE DO MONET PLAZA SHOPPING EM SANTA MARIA (RS). Revista Observatório, v. 5, n. 6, p. 786-820, 1 out. 2019.

GONÇALVES, D. S. A AULA DE INGLÊS E O DESMONTE DA EDUCAÇÃO COMO PRÁXIS POLÍTICA: Um projeto de alienação do sujeito social. Revista Observatório, v. 5, n. 6, p. 725-752, 1 out. 2019.

HAGEN, S. A. O APAGAMENTO DO SENTIDO JORNALÍSTICO DE CONSTRUÇÃO COLETIVA PELA INDIVIDUAÇÃO: "Obrigado por suas informações!". Revista Observatório, v. 5, n. 6, p. 352-379, 1 out. 2019.

KAPICIUS PLESSIM, V.; DA SILVA SOARES, F. A HISTÓRIA DA EDUCAÇÃO ENTRE FRONTEIRAS: HORIZONTES E PERSPECTIVAS DA PESQUISA EM EDUCAÇÃO. Revista Observatório, v. 5, n. 6, p. 959-971, 1 out. 2019. 


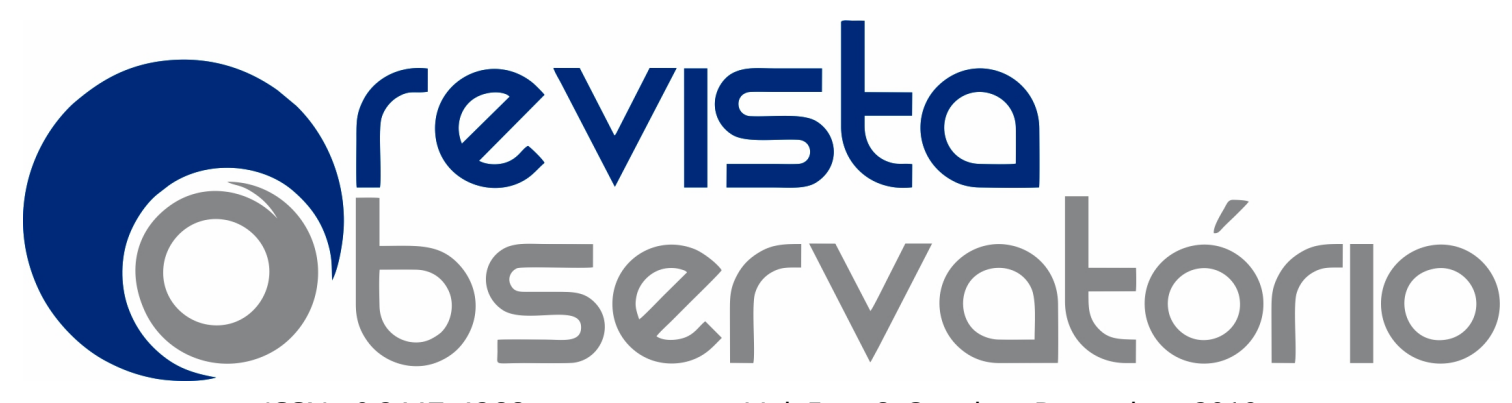

ISSN n² 2447-4266

Vol. 5, n. 6, Outubro-Dezembro. 2019

DOI: http://dx.doi.org/10.20873/uft.2447-4266.2019v5n6p26

KNEIPP, V. A.; FERREIRA DE MORAES, R. TELE-SOLIDARIEDADE EM FAMÍLIA NAS TARDES DE SÁBADO DA TV GLOBO: um estudo sobre o Caldeirão do Huck e o Estrelas Solidárias. Revista Observatório, v. 5, n. 6, p. 857-885, 1 out. 2019.

LEITE, T. S. A.; MARTINS, J. L.; DE ASSUNÇÃO, N. B.; ALMEIDA, A. A. DE; SILVA, F. D. DA; COSTA, J. M. DE A.; SANTOS, S. A. DOS. ENFERMAGEM NA PROMOÇÃO DA SUSTENTABILIDADE AMBIENTAL:uma revisão integrativa. Revista Observatório, $v$. 5, n. 6, p. 597-612, 1 out. 2019.

LIMA, L. DE. AS DIFICULDADES DE LICENCIANDOS COM O USO DE MATERIAIS AUTORAIS DIGITAIS EDUCACIONAIS. Revista Observatório, v. 5, n. 6, p. 834-856, 1 out. 2019.

MACHADO, L. S.; COSTA, T. K. DE L.; MORAES, R. M. DE. MULTIDISCIPLINARIDADE E O DESENVOLVIMENTO DE SERIOUS GAMES E SIMULADORES PARA EDUCAÇÃO EM SAÚDE. Revista Observatório, v. 4, n. 4, p. 149-172, 29 jun. 2018.

MAIA, J. S.; SILVA, M. F. V. DA. 80 ANOS NA SALA DE REDAÇÃO: Lois e Clark e o estereótipo do Jornalista. Revista Observatório, v. 5, n. 6, p. 328-351, 1 out. 2019. MARTINS, P. F. DE M.; GAMA DA SILVA, E.; MAURICIO, N. M. M. A HISTORIA DA ASSISTÊNCIA ESTUDANTIL NO ENSINO SUPERIOR BRASILEIRO: programa nacional de assistência estudantil e o aumento das classes " $D$ " e "E\&quot; nas universidade federais. Revista Observatório, v. 5, n. 6, p. 886-911, 1 out. 2019.

MELO, A. S. E. ENQUADRAMENTO HISTÓRICO LEGAL DO PROCESSO DE BOLONHA E O SEU IMPACTO NO SISTEMA DE ENSINO SUPERIOR PORTUGUÊS. Revista Observatório, v. 3, n. 6, p. 75-141, 1 out. 2017.

MIRANDA-PINTO, M. S.; MONTEIRO, A. F.; OSÓRIO, A. J. POTENCIALIDADES E FRAGILIDADES DE ROBÔS PARA CRIANÇAS EM IDADE PRÉ ESCOLAR: 3 A 6 ANOS. Revista Observatório, v. 3, n. 4, p. 302-330, 1 jul. 2017.

MIRANDA, C. G. L.; CASTRO, M. S.; SOARES-SOBRINHO, J. L. CONSTRUÇÃO COMPARTILHADA DE VÍDEO PARA EDUCAÇÃO DE IDOSOS HIPERTENSOS. Revista Observatório, v. 5, n. 6, p. 933-948, 1 out. 2019.

MIRANDA, C. G. L.; SOARES-SOBRINHO, J. L.; CASTRO, M. S. VALIDAÇÃO DE VÍDEO LÚDICO: educação em saúde de idosos hipertensos para a promoção do uso correto e seguro de medicamentos e conhecimento sobre sua doença. Revista Observatório, v. 5, n. 6, p. 821-833, 1 out. 2019.

MONTEIRO, J. C. DA S.; RODRIGUES, S. F. N.; PINHEIRO, S. C. B. APP-LEARNING: contribuições do Kahoot no Ensino de Jornalismo. Revista Observatório, v. 5, n. 6, p. 305-327, 14 maio 2019. 


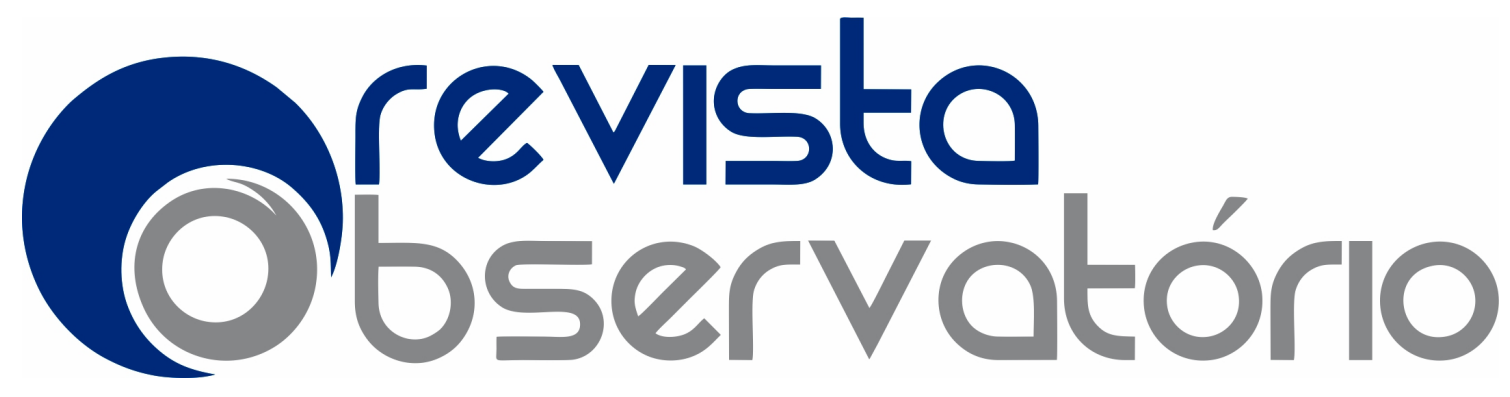

ISSN n² 2447-4266

Vol. 5, n. 6, Outubro-Dezembro. 2019

DOI: http://dx.doi.org/10.20873/uft.2447-4266.2019v5n6p26

MOURA, A. METODOLOGIAS DE APRENDIZAGEM QUE DESAFIAM OS ALUNOS, MEDIADAS POR TECNOLOGIAS DIGITAIS. Revista Observatório, v. 3, n. 4, p. 256278, 1 jul. 2017.

NASCIMENTO, W. S. DO; ZICA, C. DE O. A BUSCA POR PADRÕES NA RESOLUÇÃO DE PROBLEMAS MATEMÁTICOS NOS ANOS FINAIS DO ENSINO FUNDAMENTAL. Revista Observatório, v. 5, n. 6, p. 613-633, 1 out. 2019.

NOGUEIRA, C. C.; VAS, B. B. PERCEPÇÕES SOBRE CIBERESPAÇO E TERRITORIALIDADE DIGITAL: estudo exploratório com foco em aspectos socioculturais presentes na deep web e dark web. Revista Observatório, v. 5, n. 6, p. 272-304, 1 out. 2019.

NUNES, S. G.; PORTO JUNIOR, F. G. R.; MORAES, N. R. DE. CONHECIMENTO E ORGANIZAÇÃO: indicativos pós-Bolonha de uma sociedade em construção. Revista Observatório, v. 3, n. 6, p. 338-353, 1 out. 2017.

PEREIRA PINHEIRO, C. M.; STÜRMER, A.; WISSMANN, D.; PEDROSO, H. M. INTERATIVIDADE DIGITAL, GESTÃO DE MARCA E CONSTRUÇÃO DA REPUTAÇÃO: O Hotel Alpestre no Tripadvisor. Revista Observatório, v. 5, n. 6, p. 197-231, 1 out. 2019.

PIERINI, A. A DEMOCRACIA SEM FIM. Revista Observatório, v. 5, n. 6, p. 949-953, 1 out. 2019.

PINHO, M. J. DE; ARAÚJO, D. M. DE. TECNOLOGIAS DIGITAIS NA EDUCAÇÃO TOCANTINENSE: uma análise da contribuição para o professor. Revista Observatório, v. 5, n. 6, p. 507-528, 1 out. 2019.

REINO, L. S. A.; BUENO, T.; FALCÃO, M. G. C. FORMAÇÃO INTERDISCIPLINAR NO JORNALISMO: uma experiência de articulação entre as disciplinas de Linguagem de Programação Visual e Oratória. Revista Observatório, v. 5, n. 6, p. 249-271, 1 out. 2019.

ROCHA, J. D. T.; NOGUEIRA, C. DA R. M. FORMAÇÃO DOCENTE: uso das tecnologias como ferramentas de interatividade no processo de ensino. Revista Observatório, v. 5, n. 6, p. 578-596, 1 out. 2019.

RODRIGUES, P. M. A.; MAFRA, S. C. T.; PEREIRA, E. T. A EDUCAÇÃ̃ DE IDOSOS NA VEJA E NA FOLHA DE SÃO PAULO: dados para uma análise crítica. Revista Observatório, v. 5, n. 6, p. 473-506, 1 out. 2019.

SANTOS MOREIRA DE SOUZA, T.; NETO, A. J. P. O JORNALISMO ECONÔMICO E AS VOZES QUE FALARAM NOS JORNAIS NOS ANOS DE DEBATE DAS REFORMAS DA PREVIDÊNCIA. Revista Observatório, v. 5, n. 6, p. 634-667, 1 out. 2019. 


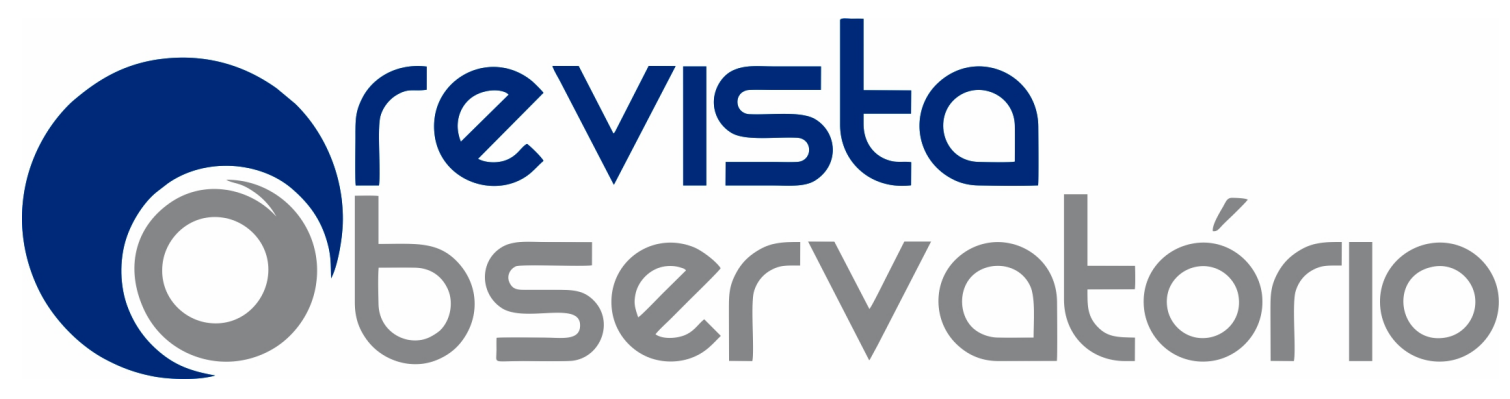

SANTOS, K. M.; ARAÚJO COSTA, C. J. DE S. TECNOLOGIAS DIGITAIS E ENSINO DE INGLÊS: uma proposta de escrita colaborativa e produção de vídeo . Revista Observatório, v. 5, n. 6, p. 547-577, 1 out. 2019.

SILVA CRUZ, A. C.; FERREIRA GADELHA, M. RELACIONAMENTO ENTRE FONTES E JORNALISTAS: estudo de caso de uma universidade pública. Revista Observatório, v. 5, n. 6, p. 404-428, 1 out. 2019.

SOARES, F. DA S. POR UMA AVALIAÇÃO DA APRENDIZAGEM COMO ATO AMOROSO: 50 anos da oficina pedagógica de Cipriano Luckesi. Revista Observatório, v. 5, n. 6, p. 972-993, 1 out. 2019.

SOARES, F. DA S.; PEREIRA， J. M.; PORTO JUNIOR, F. G. R.; MORAES, N. R. DE. NETNOGRAFIA E HUMANIDADES DIGITAIS: perspectivas e desafios. Revista Observatório, v. 5, n. 6, p. 26-45, 1 out. 2019.

SOUZA, ÉRIKA; BARBOSA, I. A. B.; SILVA, V. C. DA. INFLUÊNCIA MIDIÁTICA NA CONDENAÇÃO POPULAR ANTECIPADA. Revista Observatório, v. 5, n. 6, p. 429452, 1 out. 2019.

SPINELLI, E. M.; SANTOS, J. DE A. JORNALISMO NA ERA DA PÓS-VERDADE: factchecking como ferramenta de combate às fake news. Revista Observatório, v. 4, n. 3, p. 759-782, 29 abr. 2018.

VIANA, J.; COSTA, F. A.; PERALTA, H. APRENDIZAGENS PESSOAIS EM CONTEXTOS INFORMAIS: oportunidades criadas pela Internet. Revista Observatório, v. 3, n. 4, p. 190-231, 1 jul. 2017.

VIEIRA, S. M. F.; STEFANO, L. DE M. CULTURA DOS MEMES NO AMBIENTE CONECTIVO: identidades e criação coletiva. Revista Observatório, v. 5, n. 6, p. 700-724, 1 out. 2019.

XAVIER, R. B.; LEITE, A. M. A MORTE DA NARRATIVA E A NARRATIVA DA MORTE:uma conexão com Walter Benjamin. Revista Observatório, v. 5, n. 6, p. 994-1003, 1 out. 2019. 